\title{
The Agr Quorum Sensing System Represses Persister Formation through Regulation of Phenol Soluble Modulins in Staphylococcus aureus
}

\author{
Tao Xu ${ }^{1}$, Xu-Yang Wang ${ }^{1}$, Peng Cui ${ }^{1}$, Yu-Meng Zhang ${ }^{1}$, Wen-Hong Zhang ${ }^{1 *}$ and \\ Ying Zhang ${ }^{1,2 *}$
}

${ }^{1}$ Key Laboratory of Medical Molecular Virology, Huashan Hospital, Shanghai Medical College of Fudan University, Shanghai, China, ${ }^{2}$ Department of Molecular Microbiology and Immunology, Bloomberg School of Public Health, Johns Hopkins University, Baltimore, MD, United States

OPEN ACCESS

Edited by:

Miklos Fuzi,

Semmelweis University, Hungary

Reviewed by:

Rodolfo García-Contreras, Universidad Nacional Autónoma de México, Mexico

Dinesh Sriramulu,

Shres Consultancy

(Life Sciences), India

*Correspondence:

Ying Zhang

yzhang@jhsph.edu

Wen-Hong Zhang

zhangwenhong@fudan.edu.cn

Specialty section:

This article was submitted to Antimicrobials, Resistance

and Chemotherapy,

a section of the journal

Frontiers in Microbiology

Received: 14 July 2017 Accepted: 25 October 2017 Published: 07 November 2017

Citation:

Xu T, Wang $X-Y$, Cui P, Zhang Y-M, Zhang $W-H$ and Zhang $Y$ (2017)

The Agr Quorum Sensing System

Represses Persister Formation through Regulation of Phenol Soluble Modulins in Staphylococcus aureus.

Front. Microbiol. 8:2189. doi: 10.3389/fmicb.2017.02189
The opportunistic pathogen Staphylococcus aureus has become an increasing threat to public health. While the Agr quorum sensing (QS) system is a master regulator of S. aureus virulence, its dysfunction has been frequently reported to promote bacteremia and mortality in clinical infections. Here we show that the Agr system is involved in persister formation in $S$. aureus. Mutation of either agrCA or agrD but not RNAlll resulted in increased persister formation of stationary phase cultures. RNA-seq analysis showed that in stationary phase AgrCA AgrD and RNAlll mutants showed consistent up-regulation of virulence associated genes (lip and splE, etc.) and down-regulation of metabolism genes (bioA and nanK, etc.). Meanwhile, though knockout of agrCA or agrD strongly repressed expression of phenol soluble modulin encoding genes psma1-4, psm 1 1-2 and phenol soluble modulins (PSM) transporter encoding genes in the pmt operon, mutation of RNAlll enhanced expression of the genes. We further found that knockout of psma1-4 or psm $\beta 1-2$ augmented persister formation and that co-overexpression of PSM $\alpha$ s and PSM $\beta$ s reversed the effects of AgrCA mutation on persister formation. We also detected the effects on persister formation by mutations of metabolism genes (arcA, hutU, narG, nanK, etc.) that are potentially regulated by Agr system. It was found that deletion of the ManNAc kinase encoding gene nanK decreased persister formation. Taken together, these results shed new light on the PSM dependent regulatory role of Agr system in persister formation and may have implications for clinical treatment of MRSA persistent infections.

Keywords: Staphylococcus aureus, Agr, antibiotic, persister formation, sialic metabolism

\section{INTRODUCTION}

Staphylococcus aureus, as a leading bacterial agent of a series of hospital- and community- acquired infections, has been listed as a pathogen with high priority for research and development of new antibiotics (World Health Organization, 2017). Fail of eradication of S. aureus in clinical treatments is linked to persister formation. Persisters, first observed in staphylococci in Hobby et al. (1942), are defined as a subpopulation of bacterial cells that, without undergoing genetic changes, survive

Abbreviations: MIC, minimum inhibitory concentration; MRSA, methicillin resistant Staphylococcus aureus; MSSA, methicillin susceptible Staphylococcus aureus; PSM, phenol soluble modulins; QS, quorum sensing; TCS, two-component signal transduction system. 
the effects of high concentration of bactericidal antibiotics (Bigger, 1944). Persisters have been associated with persistent infections, presenting severe threats to patients with bacterial infections (Lewis, 2007; Fauvart et al., 2011; Zhang, 2014).

The last decade has seen much research on the mechanisms of persister formation, most of which was derived from Escherichia coli. Genes involved in toxin-antitoxin modules, trans-translation, energy production, stringent response and efflux have been found to be involved in persister formation by inducing dormancy (Dorr et al., 2009; Kim et al., 2009; Ma et al., 2010; Li et al., 2013; Pu et al., 2016). The most in-depth study so far, though not necessarily the most important, is on HipAB module in E. coli. Mutated HipA augments persister formation by phosphorylation of GltX, which in turn raises concentration of uncharged tRNA Glu, induces production of (p)ppGpp and polyP, and eventually promotes persister formation with increased production of toxins including HipA, RelE, MazF, and YafQ (Korch et al., 2003; Maisonneuve et al., 2013; Germain et al., 2015; Mitchell et al., 2016). A recent study revealed a similar mechanism that a toxin TacT promotes persister formation via acetylation of tRNA in Salmonella enterica serovar Typhimurium (Cheverton et al., 2016). Research on persister formation has also been performed in other bacteria, including Pseudomonas aeruginosa, Streptococcus mutans and Staphylococcus aureus (Singh et al., 2009; Mulcahy et al., 2010; Leung and Lévesque, 2012).

Previous studies showed that the characteristics and mechanisms of persisters in $S$. aureus are different from those in E. coli. The higher portion of persisters in stationary phase and clinical impact of Staphylococcus persisters has drawn increasing attention recently (Fauvart et al., 2011; Lechner et al., 2012). It takes more time to show distinct killing of $S$. aureus cells, and an iconic feature of E. coli persisters, called biphasic killing curve, is often absent in treatment of stationary phase S. aureus cultures with antibiotics (Lechner et al., 2012; Conlon et al., 2013; Xu et al., 2016). Multiple genes have been reported to be associated with Staphylococcus persister formation (Mechler et al., 2015; Wenjie et al., 2015; Yee et al., 2015; Xu et al., 2016). In addition, L-forms that survive high concentration of antibiotics with cell wall deficiency are believed to be a special kind of persisters (Han et al., 2014). It is intriguing that few of the homologous genes of many E. coli persister genes affect persister formation in $S$. aureus. A typical case is that no mutation of known TA modules in S. aureus affects persister levels (Conlon et al., 2016). In addition, the ppGpp molecule is not as important in S. aureus persister formation as in E. coli (Geiger et al., 2010; Corrigan et al., 2016). Nonetheless, it is worth noting that besides specific genes, decreased ATP level during entry into stationary phase is found to be a key reason of persister increase in both E. coli and S. aureus (Conlon et al., 2016; Shan et al., 2017).

Besides the difference of persister genes between E. coli and $S$. aureus, the regulatory mechanism of $S$. aureus persister formation also remains elusive. Persister formation has been defined as an outcome of stochastic induction of toxin-antitoxin activity and other persister genes influenced by the level of $\mathrm{p}$ (ppGpp) which varies stochastically in different cells during growth (Maisonneuve et al., 2013; Germain et al., 2015).
However, some key aspects of stochastic theory are unclear, especially the initiation of persister formation. QS, for its manner of regulation, is a candidate for this kind of regulation. In $P$. aeruginosa and $S$. mutans, regulation of QS has been reported (Moker et al., 2010; ?). However, whether the QS system is involved in $S$. aureus persister formation needs to be determined.

There are two known QS systems in S. aureus, LuxS and Agr. Agr is a master regulator of virulence, activated by an autoinducing peptide (AIP) that is encoded by agrD and modified and exported by AgrB (Ji et al., 1995; Morfeldt et al., 1995). Extracellular AIP molecules are processed by a TCS consisting of the histidine kinase AgrC and the response regulator AgrA (Lina et al., 1998). While most of downstream virulence genes are regulated through RNAIII, AgrA directly regulates several metabolic pathways including carbohydrate and amino acid metabolism (Dunman et al., 2001; Ziebandt et al., 2004; Queck et al., 2008). Also, Agr particularly controls expression of three specific group of virulence factors named PSMs (Wang et al., 2007; Peschel and Otto, 2013), which are transported by the Pmt system (Chatterjee et al., 2013). Joo et al. (2016) has recently reported that PSMs bind PmtR, the transcription repressor of the Pmt system, and hence promote expression of PSM transporters, showing that PSMs not only function as toxins but act as signals to regulate gene expression of $S$. aureus.

The correlation between persister formation and persistent infection is drawing increasing attention. Multiple observations of persisters in clinical infections have been reported in E. coli, $S$. aureus, $P$. aeruginosa, and Mycobacterium tuberculosis (Dhar and McKinney, 2007; Zhang et al., 2012; Cohen et al., 2013). High expression of HipA promotes persister formation and thus cause multidrug tolerance in urinary tract infections by E. coli (Schumacher et al., 2015). Despite clinical observations, a recent study showed that awakened $S$. aureus persisters are able to initiate infections and that $S$. aureus persisters, whether awake or not, possess advantages escaping from engulfment of macrophages (Mina and Marques, 2016), supporting the notion that persisters are important in initiating and establishing infections. Hence, understanding the mechanisms of $S$. aureus persister formation is critical for development of new strategies against the dangerous pathogen.

Here we report that Agr is a repressor of persister formation in stationary phase $S$. aureus. The modulation of persister formation by Agr is not RNAIII dependent, but relies on regulation of PSM expression. The findings provide new insights into the pathogenesis of $S$. aureus and clinical treatment of $S$. aureus infections.

\section{MATERIALS AND METHODS}

\section{Strains, Reagents, and Growth Conditions}

Staphylococcus aureus MRSA strain USA500 (Diep et al., 2006) as well as MSSA strains HG003 (Herbert et al., 2010) and Newman (Baba et al., 2008) were used as wild type strains. E. coli DC10B (Monk et al., 2012) was used for shuttle plasmid construction 
(Table 1). All manipulations of the strains were carried out in biosafety level 2 labs.

Lysogeny broth (LB) was used for cultivation of E. coli strains. TSB (Tryptic soy broth, Oxoid) were used for S. aureus cultivation. Anhydrotetracycline (ATc) (Sigma) was used for induction of $\sec Y$ antisense RNA during screening of mutants. During cultivation of strains that carry antibiotic resistance genes, antibiotics were added to medium at the following concentrations: chloramphenicol, $10 \mu \mathrm{g} / \mu \mathrm{l}$; ampicillin, $100 \mu \mathrm{g} / \mu \mathrm{l}$.

All strains were cultured at $37^{\circ} \mathrm{C}$ with shaking at $180 \mathrm{rpm}$ unless otherwise specified. Growth curves were determined by measuring the optical density (OD) values at $600 \mathrm{~nm}$ every hour.

\section{Gene Knockout, Complementation, and Overexpression}

Plasmid pMX10 (Xu et al., 2016), a derivate of pKOR1 (Bae and Schneewind, 2006), was used for gene knockout in S. aureus. Plasmid pRB473 (Bruckner et al., 1993) was used for complementation of gene mutations. Plasmid pRAB11 (Helle et al., 2011) was used for inducible expression of target genes. Q5 DNA polymerase (NEB) was used for all PCR experiments and restriction enzymes (NEB) for construction of recombinant plasmids in this study. Additional information of plasmids used in this study can be found in Table 1.

All sequences of primers are listed in Supplementary Table S1. To construct knockout mutants, upstream and downstream fragments of each gene were amplified with primers uf + ur and $\mathrm{df}+\mathrm{dr}$, respectively, using genome DNA of HG003, USA500 or Newman as templates. The two fragments were then used as templates to amplify a fusion fragment, which was ligated into pMX10 with T4 DNA ligase (Thermo Fisher Scientific) after digestion with corresponding restriction enzymes (Thermo Fisher Scientific). The recombinant plasmids were purified from $\mathrm{DC} 10 \mathrm{~B}$ and introduced into $S$. aureus via electro transformation. Selection of mutants were carried out following the protocol previously published (Bae and Schneewind, 2006).

To construct complementary strains, genes with their own promoters were amplified from USA500 genomic DNA. Since the coding sequences of $\operatorname{agrCA}$ and $\operatorname{agrD}$ are not directly attached to that P2 promoter of agr operon, we fused the P2 promoter sequence and the coding sequence of $\operatorname{agrCA}$ or $\operatorname{agrD}$, similar with construction of knockout plasmids described above. The PCR products were digested with corresponding restriction enzymes and ligated into pRB473. To construct plasmids for inducible overexpression, the full sequence of $p s m \alpha 1-4$ or $p s m \beta 1-2$ were amplified and inserted into pRAB11. For co-expression of PSM $\alpha$ s and PSM $\beta$ s, the coding sequences of $p s m \alpha 1-4$ and $p \sin \beta 1-2$ were fused and cloned into pRAB11. The resultant plasmids were transformed to each mutant strain via electro transformation.

\section{Susceptibility Testing}

The MIC of each antibiotic was determined in TSB medium by the conventional broth micro dilution technique. The experiments were executed in triplicate according to the protocol previously published (Andrews, 2001), following the CLSI guidelines. The MIC was defined as the lowest antibiotic concentration that inhibited visible bacterial growth after $24 \mathrm{~h}$ of incubation at $37^{\circ} \mathrm{C}$.

\section{Persister Assay}

To obtain exponential cultures, overnight $S$. aureus strains were inoculated by $1: 100$ into TSB and cultured for about $1.5 \mathrm{~h}$ to an OD600 of 0.5-0.6. Stationary phase cultures were grown to $\sim 14 \mathrm{~h}$. For complementary strains, the cultures were grown in TSB with $10 \mu \mathrm{g} / \mu \mathrm{l}$ chloramphenicol. For strains for inducible overexpression, $125 \mathrm{ng} / \mu \mathrm{l}$ ATc was added to each sample at $6 \mathrm{~h}$. After washing twice with PBS, cultures were allotted in $14 \mu \mathrm{l}$ tubes and challenged with one of the four antibiotics: levofloxacin at $50 \mu \mathrm{g} / \mu \mathrm{l}$, gentamicin at $50 \mu \mathrm{g} / \mu \mathrm{l}$, oxacillin at $5 \mu \mathrm{g} / \mu \mathrm{l}$, and vancomycin at $50 \mu \mathrm{g} / \mu \mathrm{l}$. Serial dilutions were performed and $100 \mu \mathrm{l}$ aliquots were spotted on TSA plates for colonyforming unit (CFU) counting at different time points. Results were obtained from three biological duplicates and significance was assessed with $t$-test.

\section{RNA Isolation, mRNA Enrichment and Sequencing}

Staphylococcus aureus strain USA500, $\Delta$ agrD, $\triangle \operatorname{agrCA}$, and $\triangle R N A I I I$ were incubated for $14 \mathrm{~h}$ and harvested. Total RNA was purified following protocol previous reported (Atshan et al., 2012). Briefly, cultures were centrifuged, resuspended in $100 \mu \mathrm{l}$ diethylpyrocarbonate (DEPC) $\mathrm{H}_{2} \mathrm{O}$. Each aliquot was added with $100 \mu \mathrm{l} \mathrm{phenol/chloroform}(1: 1)$, incubated at $70^{\circ} \mathrm{C}$ for $30 \mathrm{~min}$ and centrifuged. RNA was purified from the supernatant of each sample using RNeasy Mini Kit (Qiagen), following protocol provided.

The Bioanalyzer 2100 RNA-6000 Nano Kit (Agilent Technologies) was used to detect the quality of total RNA. The Ribo-Zero ${ }^{\text {TM }}$ Gold Kit (Illumina) was used to remove 16S and $23 \mathrm{~S}$ rRNAs. The cDNA libraries with cDNA length ranging from 150 to 250 bp were generated from the mRNA samples using the TruSeq Illumina Kit (Illumina), following instructions from the manufacturer.

RNA-seq was performed by Shanghai Biotechnology Corporation (Shanghai, China) with HiSeq2500 Ultra-HighThroughput Sequencing System (Illumina). The total numbers of reads were assessed and quantified with the Cufflinks suite of tools. The transcript sequencing data were submitted to the NCBI Sequence Read Archive and deposited under the accession number SRR5277864.

\section{Quantitative Real-Time PCR}

For qRT-PCR, RNA samples were extracted from S. aureus strains as described above. Reverse transcription was carried out using the cDNA Synthesis Kit (Bio-Rad, United States). The qRT-PCR experiments were performed using SYBR Green PCR Kit (Takara) on Applied Biosystems 7500 Real-Time PCR System (Thermo Fisher Scientific). The sequences of primers for detection of target genes and primers for endogenous control gene $r r s 1$ (16S RNA) are listed in Supplementary Table S1. The $2^{-\Delta \Delta C_{\mathrm{T}}}$ method (Livak and Schmittgen, 2001) was used for analysis of relative 
TABLE 1 | Strains and plasmids used in this study.

\begin{tabular}{|c|c|c|}
\hline Strain/plasmid & Specification & Reference \\
\hline \multicolumn{3}{|l|}{ Strains } \\
\hline DC10B & A DC10B derivate for plasmid amplification & Monk et al., 2012 \\
\hline USA500 & MRSA strain from a clinical sample & Diep et al., 2006 \\
\hline Newman & An MSSA strain from a clinical sample & Baba et al., 2008 \\
\hline HG003 & An MSSA strain, derivate from NCTC8325 & Herbert et al., 2010 \\
\hline$\Delta$ AgrCA & The agrCA mutant of USA500 & This study \\
\hline Newman $\Delta$ AgrCA & The agrCA mutant of Newman & This study \\
\hline $\mathrm{HG} 003 \Delta \mathrm{AgrCA}$ & The agrCA mutant of HG003 & This study \\
\hline$\Delta \mathrm{AgrD}$ & The agrD mutant of USA500 & This study \\
\hline$\triangle$ RNAIII & The RNAIII mutant of USA500 & This study \\
\hline$\Delta l u x S$ & The luxS mutant of USA500 & This study \\
\hline$\Delta \mathrm{ArIRS}$ & The arIRS mutant of USA500 & This study \\
\hline$\Delta$ GraRS & The graRS mutant of USA500 & This study \\
\hline$\Delta$ NanK & The nanK mutant of USA500 & This study \\
\hline$\Delta$ AgrCA $\Delta$ NanK & The agrCA mutant of USA500 with additional knockout of nanK & This study \\
\hline$\Delta$ HutU & The hutU mutant of USA500 & This study \\
\hline$\Delta \mathrm{NarG}$ & The narG mutant of USA500 & This study \\
\hline$\Delta$ ArcA & The arcA mutant of Newman & This study \\
\hline$\Delta \operatorname{ArcR}$ & The arcR mutant of Newman & This study \\
\hline$\Delta \mathrm{MtID}$ & The $m t / D$ mutant of Newman & This study \\
\hline$\Delta \mathrm{lmrP}$ & The imrP mutant of Newman & This study \\
\hline$\Delta \mathrm{RhbC}$ & The rhbC mutant of Newman & This study \\
\hline$\Delta \mathrm{lpdC}$ & The ipdC mutant of Newman & This study \\
\hline \multicolumn{3}{|l|}{ Plasmids } \\
\hline pRAB11 & ATc inducible shuttle plasmid, $\mathrm{Cm}^{R}, \mathrm{Amp}^{\mathrm{R}}$ & Helle et al., 2011 \\
\hline $\mathrm{pMX10}$ & A pKOR1 derivate for gene knockout, $\mathrm{Cm}^{\mathrm{R}}, \mathrm{Amp}^{\mathrm{R}}$ & This study \\
\hline pRB473 & A shuttle plasmid for complementary construction, $\mathrm{Cm}^{\mathrm{R}}, \mathrm{Amp}^{\mathrm{R}}$ & Bruckner et al., 1993 \\
\hline pRBagrCA & Complementary plasmid for AgrCA & This study \\
\hline pRBagrD & Complementary plasmid for AgrD & This study \\
\hline pRBnanK & Complementary plasmid for NanK & This study \\
\hline pRABpsm $\alpha$ & Overexpression plasmid for $p s m \alpha 1-4$ & This study \\
\hline pRABpsm $\beta$ & Overexpression plasmid for $p s m \beta 1-2$ & This study \\
\hline $\mathrm{pRABpsm} \alpha \beta$ & Overexpression plasmid for $p s m \alpha 1-4$ and $p s m \beta 1-2$ & This study \\
\hline
\end{tabular}

$\mathrm{Cm}^{R}$, chloramphenicol resistance; $A m p^{R}$, ampicillin resistance.

gene expression data that were obtained from three independent experiments.

\section{L-Form Assay}

L-form test was performed following protocol previously published (Han et al., 2014). Briefly, L-form induction medium (LIM) was prepared with brain heart infusion (BHI) supplemented with 1\% agar, 10\% fetal bovine serum (Gibco, United States), $3.5 \%$ sodium chloride, $20 \%$ sucrose, $0.125 \%$ magnesium sulfate, and $600 \mu \mathrm{g}(1000$ units)/ $\mu \mathrm{l}$ of Penicillin G (Sigma). S. aureus Newman strain was grown overnight to stationary phase. Undiluted cultures were spotted onto LIM and incubated at $33^{\circ} \mathrm{C}$ for $7-10$ days. The L-form colonies were detected by inverted microscope (Nikon).

\section{Measurement of Intracellular ATP Level}

Stationary phase cultures of $S$. aureus strains were mixed with BacTiter-Glo ${ }^{\mathrm{TM}}$ reagent from the BacTiter-Glo ${ }^{\mathrm{TM}}$
Microbial Cell Viability Assay (Promega, United States) by 1:1. The luminescence was detected with an FB12 luminometer (Berthold). Data was neutralized according to CFU counting of each culture.

\section{Statistics}

The significance of experimental differences in persister assay and intracellular ATP assay was evaluated with two-tailed unpaired $t$-test (two groups).

\section{RESULTS}

\section{Agr System Regulates Persister Formation}

We constructed mutants via homologous recombination for Agr and LuxS QS systems, as well as two TCSs ArlRS and GraRS involved in virulence regulation. Considering the complexity of 
Agr system, mutation of the AIP coding gene agrD and the Agr controlled regulatory RNA molecule gene RNAIII were also constructed (Table 2). The growth of each mutant strain of USA500 was measured. As shown in Figure 1A, none of the knockout mutants affected bacterial growth, indicating these genes are not required for normal bacterial growth in log phase.

To address the role of the above genes in persister formation, several antibiotics were used to treat exponential phase cultures of USA500 and the mutant strains. As a result, none of the mutants affected persister formation to any of the antibiotics (Supplementary Figures S1A-D). Stationary cultures of MRSA can be extremely difficult to kill by multiple antibiotics, even after 5 -day treatment at high concentrations of antibiotics (Lechner et al., 2012; Conlon et al., 2013). Based on our previous observation that levofloxacin can cause prominent killing of S. aureus USA500 strain (Xu et al., 2016), we used levofloxacin in persister assays of stationary phase cultures in this study. Among the strains, USA500 $\triangle a g r C A$ or USA500 $\triangle a g r D$ showed significant increase of persister formation to levofloxacin in stationary phase while knockout of RNAIII slightly reduced persister formation. At the 5th day of treatment, the CFU count of USA500 $\triangle$ agrCA or USA500 $\triangle$ agrD dropped $\sim 1$ $\log _{10}$ compared to that of the 1st day, while the CFU count of USA500 $\Delta$ RNAIII $(\sim 10 \mathrm{CFU} / \mu \mathrm{l})$ was even lower than that of the control strain USA500 $\left(\sim 10^{2} \mathrm{CFU} / \mu \mathrm{l}\right)$. The impacts of knockout of $\operatorname{agrCA}$ or $\operatorname{agrD}$ were reversed by complementation of each gene (Figure 1B). Mutation in luxS, arlRS, or graRS showed no apparent impact on persister formation of stationary phase cultures (Supplementary Figure S1E).
To investigate whether the impact on persister formation by Agr system is ubiquitous in $S$. aureus, we constructed agrCA mutants in two methicillin sensitive S. aureus (MSSA) strains Newman and HG003. While none of the knockout mutations affected growth (Figure 1C), both mutant strains showed augmented persister formation in stationary phase, but only to levofloxacin (Figure 1D).

\section{RNA-seq Analysis of Stationary Phase Regulation by Agr System}

The Agr system functions by regulating expression of its target genes, either by direct regulation with AgrA or by indirect regulation through RNAIII (George and Muir, 2007; Queck et al., 2008). As we have shown, the difference in bacterial survival between $\triangle a g r C A$ and $\triangle R N A I I I$ mutants indicates that the regulation of persister formation by Agr system is RNAIII independent. According to the study by Queck et al. (2008) with RNA-seq analysis of 4-h cultures of $S$. aureus MW2 strain and its mutants of agr or RNAIII, Agr regulated genes that are RNAIII independent mainly consist of metabolism associated genes and PSM genes (Queck et al., 2008). Since the effects of AgrCA mutation were observed only in stationary phase, we performed RNA-seq with stationary phase cultures of USA500 and its mutants of $\operatorname{agrCA}, \operatorname{agrD}$, and RNAIII, to further investigate the RNAIII independent regulatory mechanisms of Agr system on persister formation.

As shown in the Heatmap (Figure 2), the three mutants caused significant changes to transcription of different genes, compared

TABLE 2 | Genes detected for persister formation in this study.

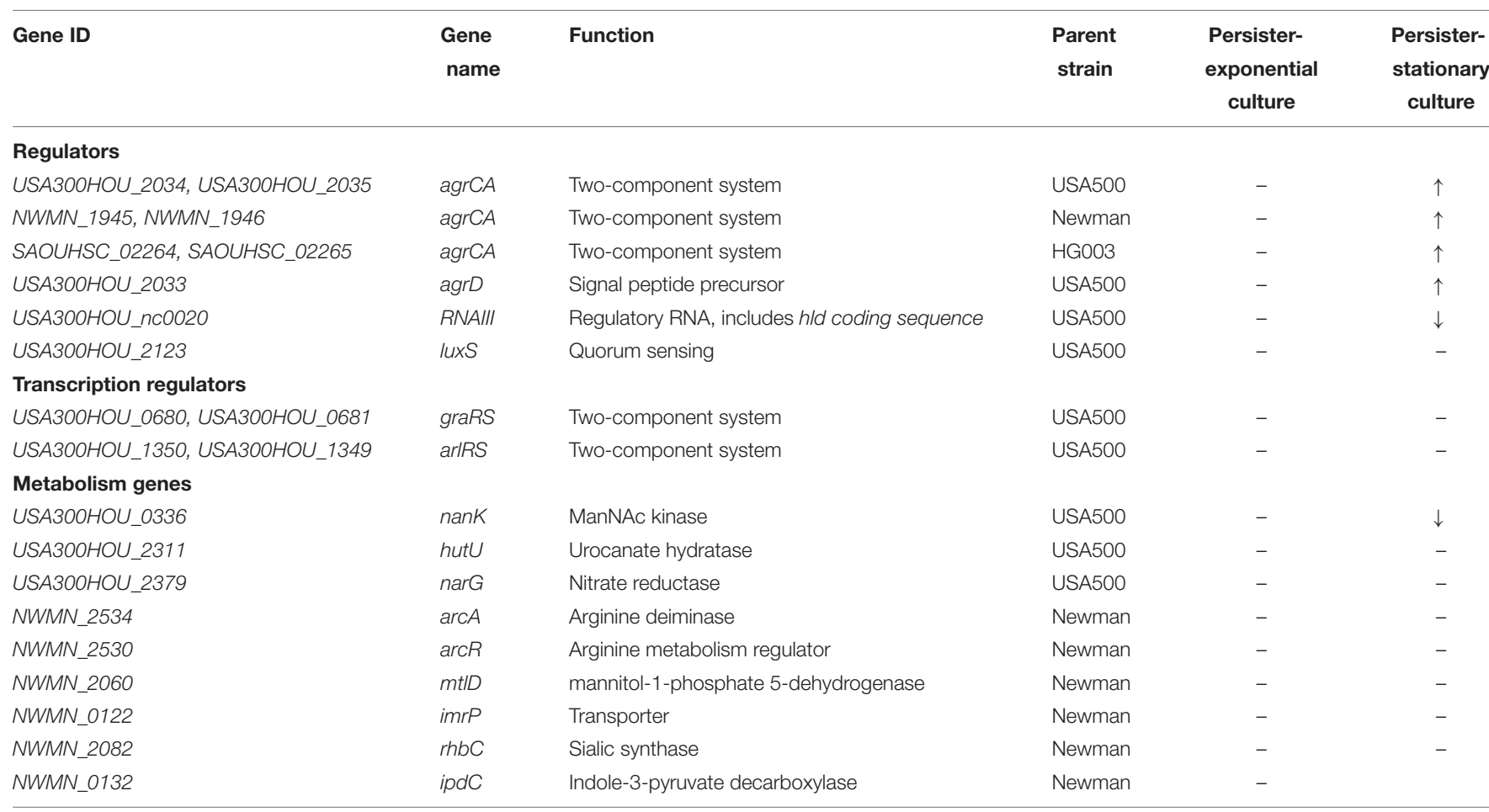

$\uparrow$, increase; $\downarrow$, decrease; -, no significant difference. 
A

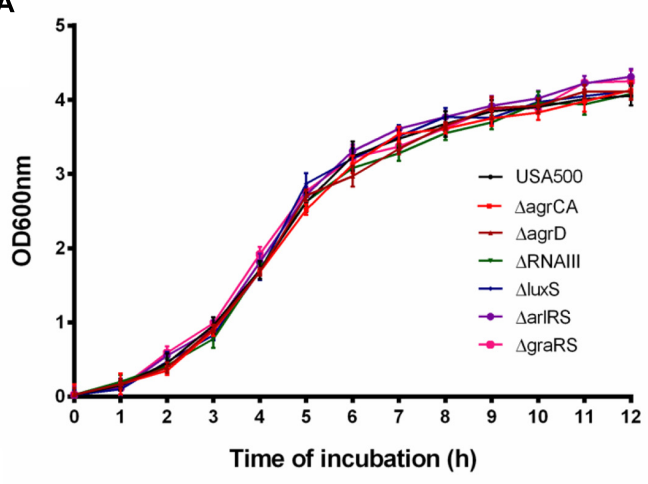

C

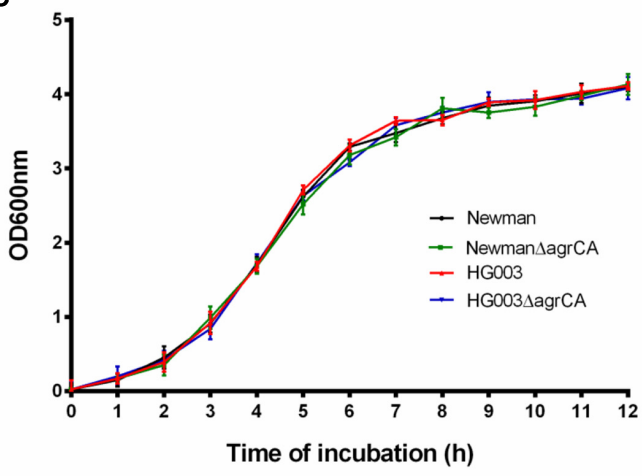

B

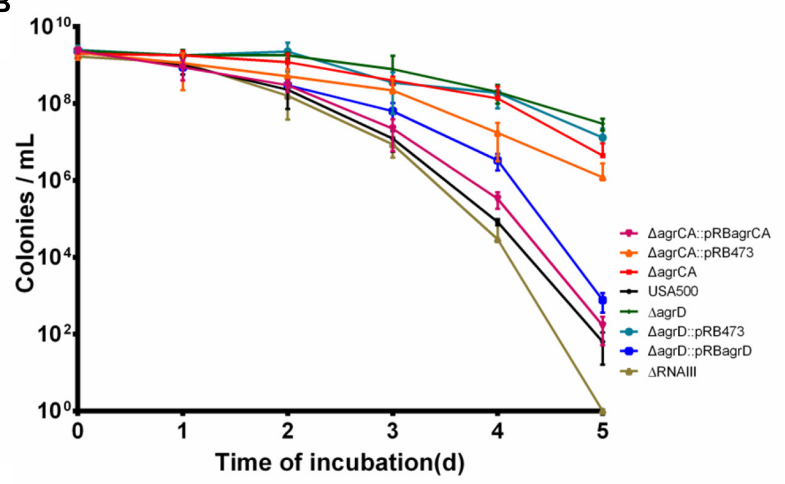

D

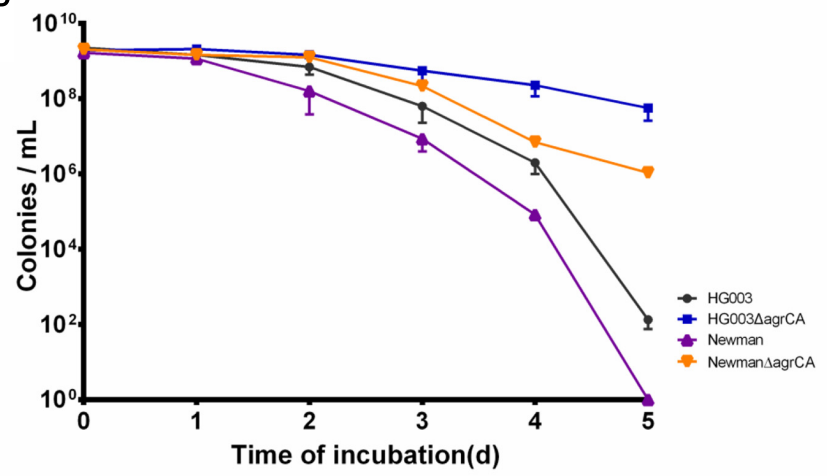

FIGURE 1 | Agr system regulates S. aureus persiser levels. (A,C) Growth curve of different knockout strains compared with their parent strains. (B,D) Stationary phase cultures of knockout strains and the parent strains were treated with $50 \mu \mathrm{g} / \mu \mathrm{l}$ levofloxacin. The limit of detection was $100 \mathrm{CFU} / \mu \mathrm{l}$ throughout all killing experiments. Results are representative of three independent experiments.

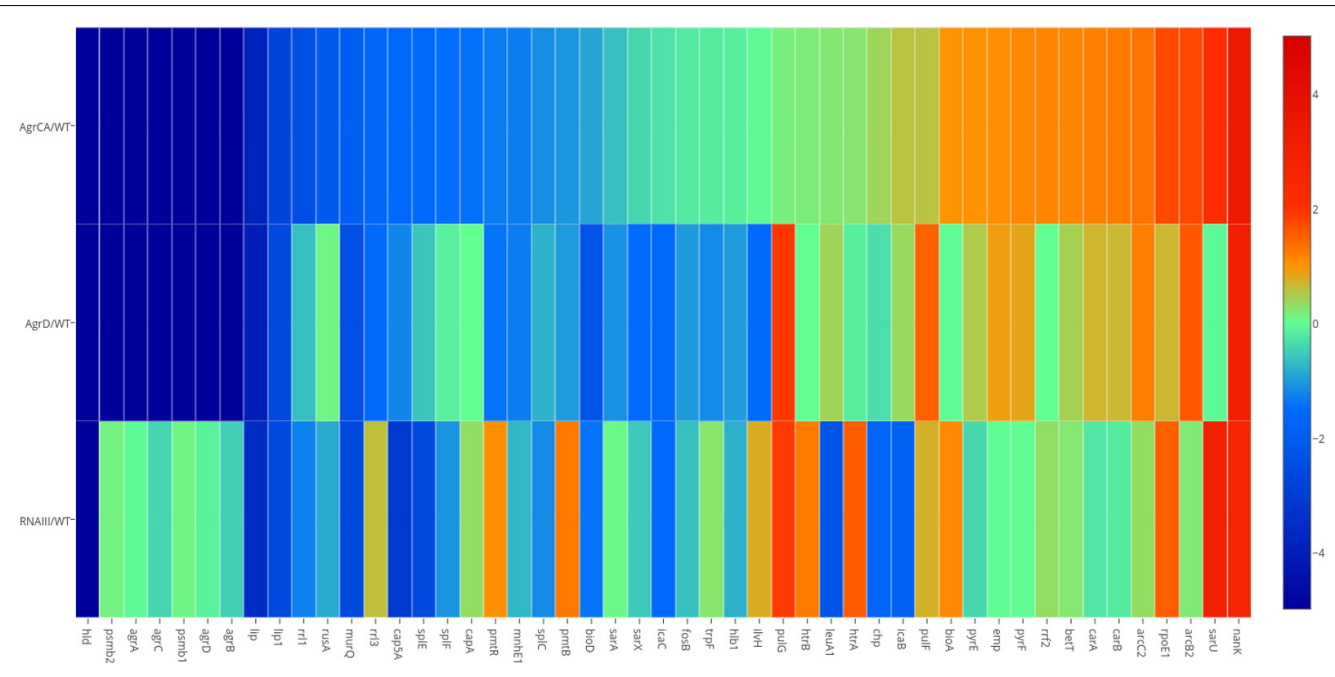

FIGURE 2 | Transcriptional changes caused by mutation of agrCA, agrD and RNAIll in USA500. Based on results of RNA-seq, comparison ( $p$ < 0.05) of transcriptional levels of each strain stress with that of USA500 are shown in columns. Genes up regulated in each deletion strain are represented in red, whilst genes down regulated in green. The enriched GO terms in the resulting clusters are shown. The map was painted with MEV software. A3, $\triangle$ agrCA; D4, $\triangle a g r D ; R 5$, $\triangle R N A I I ;$ WT, wild type.

with the parent strain USA500. In the $\operatorname{agr} C A$ and $\operatorname{agrD}$ mutants, expression of metabolism genes including bioA, pyrF, and nanK were upregulated while several pathogenicity associated genes (lip, lip1, splE, and $s p l F$, etc.) were down regulated; meanwhile, the expression of PSM associated genes hld, psm $\beta 1$, $p s m \beta 2$, $p m t R$, and $p m t B$ were strongly repressed. Comparison 


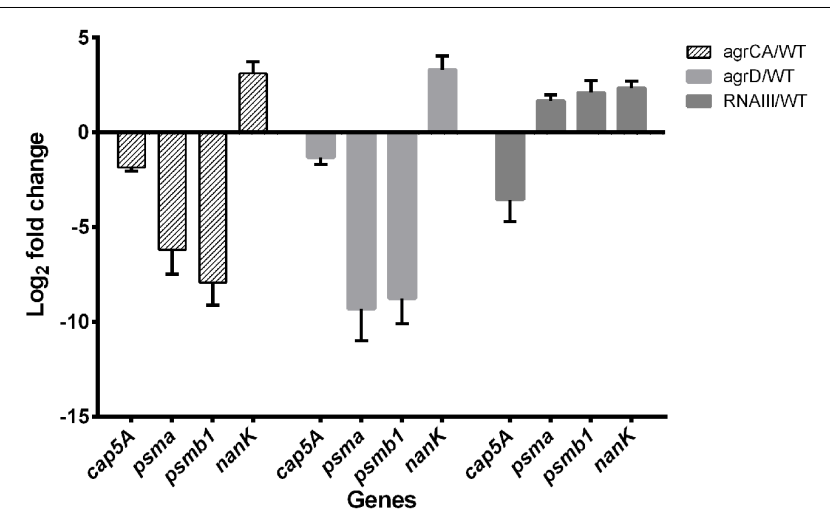

FIGURE 3 | Validation of RNA-seq by quantitative real-time PCR. Relative mRNA levels of transcripts from to USA500 and agrCA, agrD as well as RNAIII mutant strains mutant grown to 12-14 were determined. RNA was obtained from the same samples for RNA-seq. Bars show the fold change of each mutant vs. USA500 and error bars indicate standard deviations calculated with the $2^{-\Delta \Delta C_{t}}$ method based on three independent experiments.

of USA500 $\Delta$ RNAIII with USA500 $\Delta$ agrCA strain showed consistent down-regulation of virulence genes (lip, lipl, splE, and $s p l F$, etc.) and up-regulation of metabolism genes (bioA, rpoE1, and $n a n K$, etc.), while unlike in USA500 $\Delta$ agrCA, expression of $p s m \beta 1, p s m \beta 2, p m t R$, and $p m t B$ in USA500 $\Delta$ RNAIII were up regulated (Supplementary Tables S2, S4). It is worth mentioning that though the impact on gene expression by AgrD deletion was similar as that of AgrCA deletion, expression of several genes including $p u l G$ and sarU were regulated by AgrCA and AgrD differently (Supplementary Tables S2, S3).

The RNA-seq results were validated by detecting transcription levels of several genes with Quantitative Real-time PCR. All samples showed similar fold change with those from RNA-seq results (Figure 2). The expression levels of the co-transcribed psma1-4 genes did not show up in RNA-seq data analysis of either strain, probably because the sizes of the four genes are too small to be included in the cDNA library. We detected mRNA level of $p s m \alpha$ genes using primers for amplification of an 89-bp segment from the psm $\alpha$ operon, and found that the impact on PSM $\alpha$ s by depletion of $\operatorname{agrCA}$, $\operatorname{agrD}$ or RNAIII were similar with that on PSM $\beta$ s (Figure 3).

\section{The Functional Roles of PSMs in Agr Regulated Persister Formation}

Based on the observation of different impacts on persister formation by mutation of AgrCA and RNAIII, we hypothesized that the gene(s) are regulated differently by AgrCA and RNAIII. It has been reported that AgrCA strongly up-regulates while RNAIII down-regulates expression of PSM $\alpha$ s and PSM $\beta$ s in postexponential phase (Queck et al., 2008). Here we showed the similar trends with regulation of psm genes by Agr CA and RNAIII in stationary phase, where AgrCA up regulated and RNAIII down regulated expression of both $p s m \alpha 1-4$ and $p s m \beta 1-2$ (Figures 2, 3).

We further constructed knockout strains $p s m \alpha 1-4$ or $p s m \beta 1$ 2, which did not affect cell growth (Supplementary Figure S2). Persister assay showed that for stationary cultures, knockout of psma 1-4 or psm $\beta 1-2$ resulted in significant enhancement of persister formation, similar to the effects of agrCA knockout. In addition, complementation of $p s m \alpha 1-4$ or $p s m \beta 1-2$ reversed promotion of persister formation of each mutant, respectively (Figure 4A).

To investigate whether PSMs are the key factors in Agr regulated persister formation, we constructed overexpressing
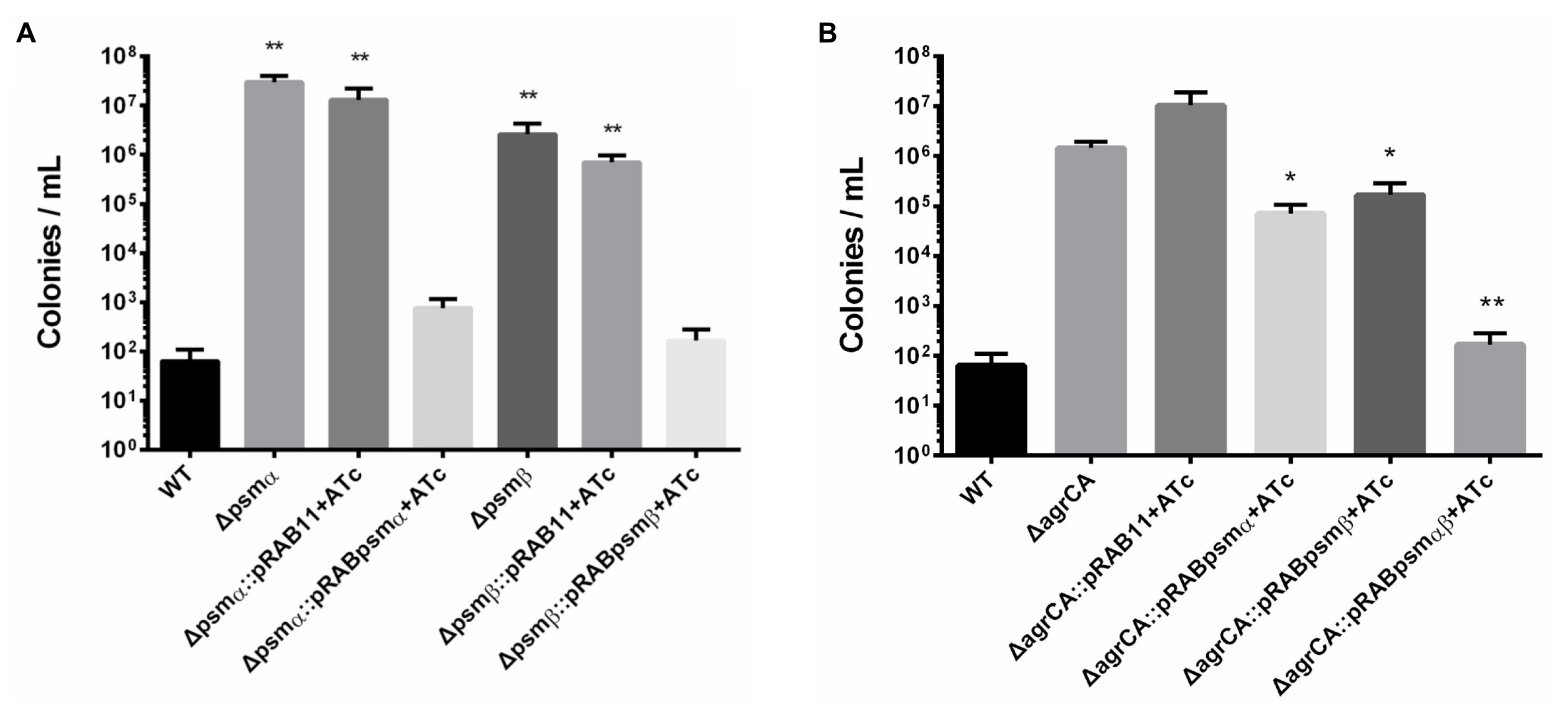

FIGURE 4 | Phenol soluble modulins affect S. aureus persister formation. (A,B) Stationary phase USA500, knockout strains, complementary strains (based on pRB473) and overexpression strains (based on pRAB11) were treated with levofloxacin for 5 days. Results are representative of three independent experiments. ${ }^{*} p<0.05,{ }^{* *} p<0.01 ;$ t-tests vs. corresponding control sample $(\Delta a g r C A)$. 
A

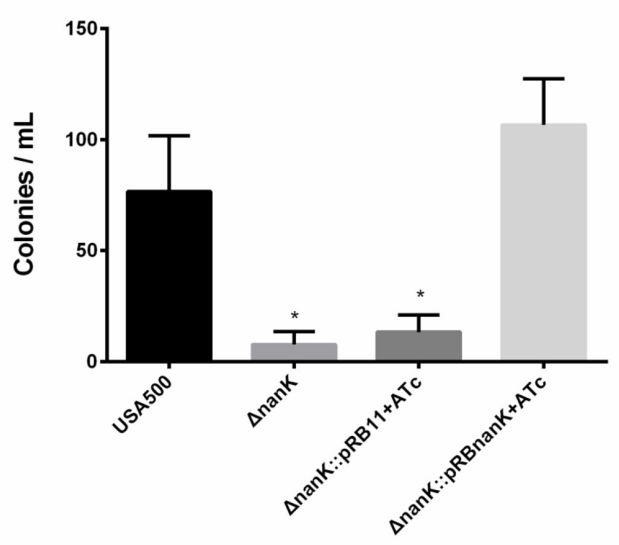

B

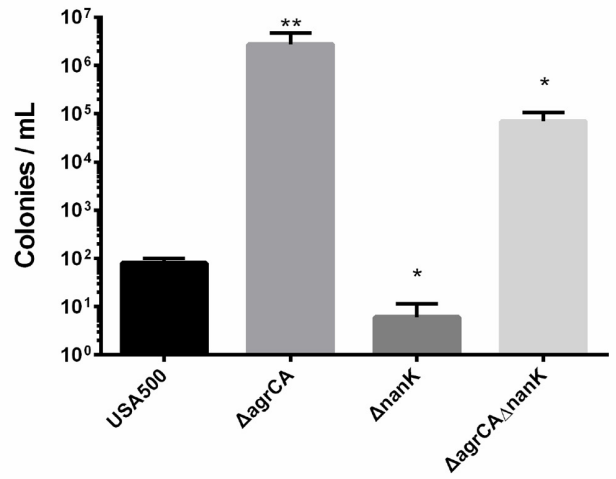

C
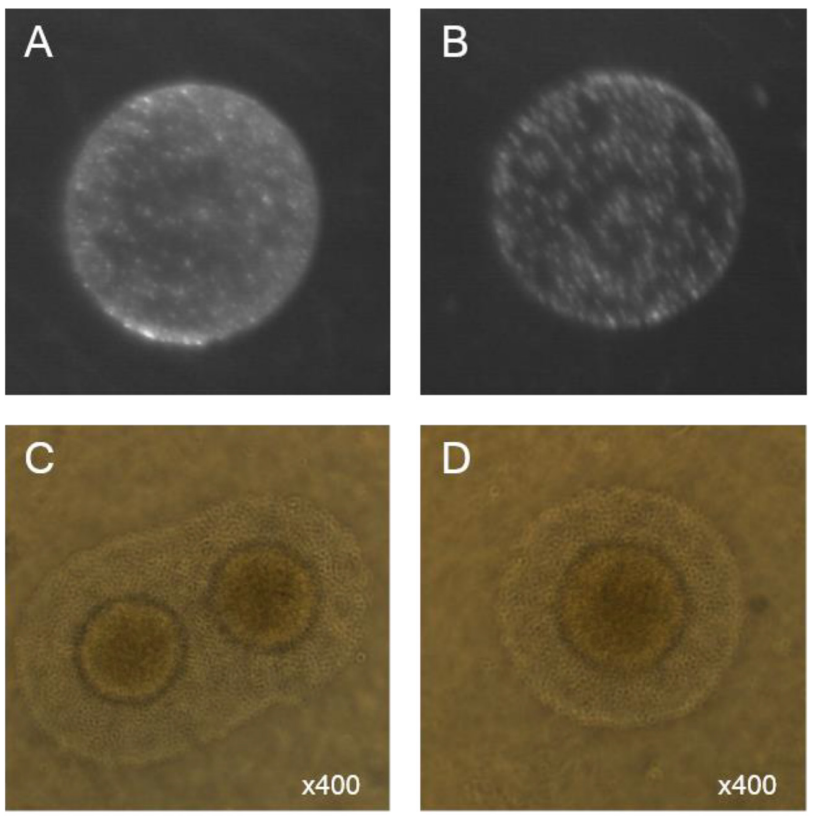

Newman

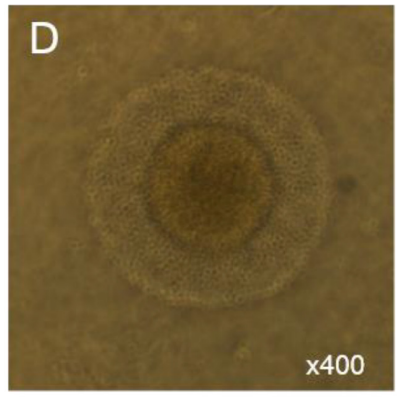

$\Delta$ nanK

FIGURE 5 | Comparison of persister formation and L-form formation of S. aureus strains. (A,B) Stationary phase USA500, knockout strains, complementary strains (based on pRB473) and double mutants were treated with levofloxacin. Results are representative of three independent experiments. ${ }^{*} p<0.05,{ }^{*} p<0.01 ; t$ tests vs. corresponding control (WT) samples. (C) S. aureus USA500 strain and its nanK mutant were plated on LIM. (C,D) L-form colonies observed under microscope at $400 \times$ magnification. The typical "fried egg" morphology can be observed from both strains.

plasmids for $p s m \alpha 1-4, p s m \beta 1-2$ or both of them co-transcribed in one operon. Expressions of PSM genes are induced by ATc and not affected by absence of AgrA. Overexpression of psma14 , psm $\beta 1-2$ or both genes were capable of complementing the mutation of AgrCA on stationary phase persister formation, and the co-expressed PSM $\alpha$ s and PSM $\beta$ s showed the strongest effects (Figure 4B). These results indicate that PSM $\alpha$ s and PSM $\beta$ s are key downstream factors for persister regulation by the Agr system.

\section{NanK Is Involved in Persister Formation and L-Form Formation}

Persister formation is closely related to dormancy with low metabolic state. To find more genes responsible for Agrmediated persister formation, we picked eight more metabolism associated genes ( $h u t U, \operatorname{narG}, \operatorname{arcA}, \operatorname{arcR}, m t l D, i m r P, r h b C$, and nanK) (Table 2) according to results of RNA-seq experiments performed by Queck et al. (2008) and also by us. Among these genes only nanK mutant showed decreased persister formation to levofloxacin in stationary phase, compared with USA500 strain while knockout of nanK did not affect bacterial growth (Supplementary Figure S3). In addition, the effects could be reversed by introduction of complementary plasmid pRBnanK (Figure 5A).

Since nanK expression is strongly up regulated in USA500 $\triangle a g r C A$ strain which showed enhanced persister formation, we seek to detect whether knockout of nanK could affect persister formation of USA500 $\triangle$ agrCA. However, the double mutant showed similar persister level with that of USA500 $\Delta$ agrCA (Figure 5B).

Sialic acid metabolism is an important bioavailable energy source in stationary phase (Olson et al., 2013). The Neu5Ac catabolic pathway is a complex process catalyzing $\mathrm{N}$-acetylneuraminic acid (Neu5Ac) into Fructose-6P (Fru$6 \mathrm{P}$ ), which can be utilized in central metabolism or cell wall metabolism. NanK, the ManNAc kinase, phosphorylates ManNAc at the C-6 position to yield ManNAc-6P plays an important role in the pathway (Almagro-Moreno and Boyd, 2009; Olson et al., 2013). To assess whether mutations of NanK or Agr system alter persister formation by affecting synthesis of ATP, intracellular ATP levels of stationary phase cultures of USA500 and its mutant strains of nanK, agrCA, agrD, RNAIII, psma1-4, and $p \sin \beta 1-2$ were measured. However, no significant difference in ATP levels between these strains was found (Supplementary Figure S4). 
TABLE 3 | Minimum inhibitory concentration (MIC) $(\mu \mathrm{g} / \mu \mathrm{l})$ of Staphylococcus aureus strains used in this study.

\begin{tabular}{|c|c|c|c|c|}
\hline Strains & Gentamicin & Levofloxacin & Oxacillin & Vancomycin \\
\hline USA500 & 2 & 0.5 & 0.2 & 0.5 \\
\hline USA500 $\Delta$ agrCA & 2 & 0.5 & 0.2 & 0.5 \\
\hline USA500 $\Delta$ agrD & 2 & 0.5 & 0.2 & 0.5 \\
\hline USA500 $\Delta$ RNAIII & 1 & 0.5 & 0.2 & 0.5 \\
\hline USA500 $\Delta \mathrm{psm} \alpha$ & 2 & 0.5 & 0.2 & 0.5 \\
\hline USA500 $\Delta \mathrm{psm} \beta$ & 2 & 0.5 & 0.2 & 0.5 \\
\hline Newman & 1 & 0.25 & 0.05 & 0.5 \\
\hline NewmansagrCA & 1 & 0.25 & 0.05 & 0.5 \\
\hline HG003 & 1 & 0.25 & 0.1 & 0.5 \\
\hline HG003 $\Delta$ agrCA & 1 & 0.25 & 0.1 & 0.5 \\
\hline
\end{tabular}

We have found in our previous work that the glycerol uptake facilitator GlpF participates in both persister and L-form formation, indicating a close relationship between the two strategies bacteria use to survive challenge of antibiotics (Han et al., 2014). Having found that NanK deletion attenuated persister formation, we sought to investigate whether NanK is also involved in L-form formation. As shown in Figure 5C, $\Delta$ nanK formed fewer L-form colonies, while the shape and size of individual bacterial cells were similar with that of the wild type strain.

\section{DISCUSSION}

Staphylococcus aureus persister mechanisms are different from those in E. coli persisters in several aspects. In E. coli, the influence of mutation of a gene on persister formation is generally consistent, with variations on growth phases or type of antibiotics. However, S. aureus persister genes often affect persister formation only in exponential phase or stationary phase (Han et al., 2014; Xu et al., 2016). Also, the difference in persister formation can sometimes be observed when treated with specific antibiotics (Mechler et al., 2015; Wenjie et al., 2015; Yee et al., 2015). We also showed in this study that the impacts on persister formation by AgrCA and Agr regulated genes were only found from treatment with levofloxacin. However, the underlying mechanisms for the difference between $S$. aureus and E. coli persister formation are far from being unveiled and require further study.

Agr is one of the master regulators of virulence in S. aureus. Mutations of Agr system genes have been shown to strongly attenuate virulence (George and Muir, 2007; Cheung et al., 2011; Bünter et al., 2016). Based on its importance, several studies have focused on developing anti-Agr strategies in S. aureus, and obvious repression of pathogenicity has been confirmed (Gray et al., 2013; Murray et al., 2014; Khan et al., 2015). However, though anti-Agr strategies seem promising, many groups have reported that Agr dysfunction promotes persistent bacteremia (Fowler et al., 2004; Park et al., 2013; Kang et al., 2017), permits abscess formation (Das et al., 2016), and increases mortality among patients with $S$. aureus bacteremia, especially the most severe cases (Schweizer et al., 2011). The unexpected correlation of Agr dysfunction and worsened outcome of infection is intriguing and the reason remains unclear (Painter et al., 2014).

Previous studies showed that selection for loss of Agrdefective strains was mainly by healthcare environment including antibiotic treatment (Butterfield et al., 2011; Smyth et al., 2012). A possible explanation is that, for unknown reasons, Agr dysfunction decreases vancomycin bactericidal activity (Rose et al., 2007; Tsuji et al., 2009). However, the impacts of Agr dysfunction on MIC of vancomycin were about two to four fold. Meanwhile, we did not observe MIC change of the $\operatorname{agrCA}$ mutant treated with vancomycin or any other antibiotics used in this study (Table 3). Another hypothesis is that Agr dysfunction might help $S$. aureus escape host immune attack by reducing expression of multiple virulence genes regulated by Agr system (Malachowa et al., 2011). However, it is also reported that Agr dysfunction also promotes neutrophil lysis after phagocytosis (Surewaard et al., 2013). Therefore, the eventual outcome of interaction of host immune system and Agr dysfunction is yet to be determined.

Based on our study, we provide another possible explanation that Agr dysfunction might promote persistent infection by increasing persister formation through down-regulation of PSM $\alpha$ s and PSM $\beta$ s in S. aureus. This is demonstrated by elevated persister formation of Agr mutants in our study. The multifunctional PSMs have been reported to help S. aureus cope with immune system by killing human neutrophils (Wang et al., 2007). PSMs also mediate maturation and detachment of late phase staphylococcal biofilms (Otto, 2013), which significantly promotes staphylococcal persister formation (Shapiro et al., 2011; Conlon et al., 2015). Besides extracellular effects, PSMs also act as an intracellular signal to regulate gene expression. So far, PSMs have been found to bind only PmtR, which controls expression of genes in the pmt operon (Joo et al., 2016). More research is required to investigate whether PSM $\alpha$ s and PSM $\beta$ s affect persister formation through PmtR, and if so, how PmtR regulate persister formation by controlling its target genes. Besides in vitro studies, more studies are required to address the regulation of persister formation by Agr system through PSMs in animal models, where the host immune system plays a role or additional antibiotic treatment may be applied to interrogate the role of Agr and PSM in persistent infection. Nonetheless, based on the clinical reports and our findings, we argue that the application of anti-Agr therapy should be more cautious especially when treating patients 


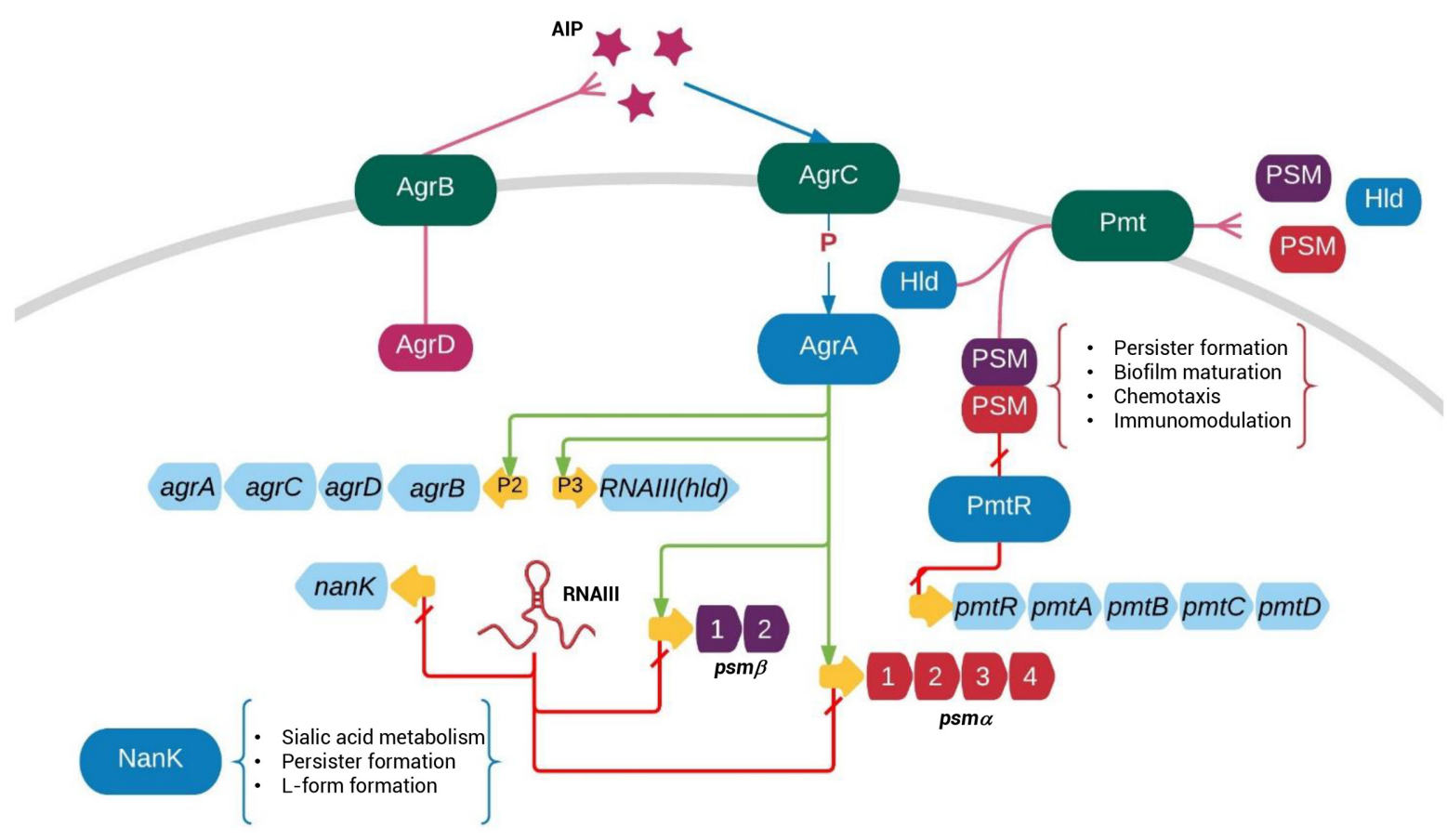

FIGURE 6 | Regulation of persister formation is part of the Agr quorum-sensing regulatory network. The agr operon encodes a signal molecule AIP from P2 promoter and a regulatory RNA molecule RNAlll from P3 promoter. While AgrA up-regulates expression of P2, P3, NanK, and PSM expression, RNAlll negatively regulate NanK and PSM expression. NanK is involved in sialic metabolism and persister formation. PSM $\alpha$ s and PSM $\beta$ s represses persister formation through unclear mechanisms. The "P" between AgrC and AgrA indicates phosphorylation.

with persistent $S$. aureus infections, in particular for those with immunodeficiency.

We wondered what are the key factors in Agr mediated persister regulation. Agr system regulates different aspects of $S$. aureus biologic processes in both RNAIII dependent and RNA independent pathways. It is worth noticing that the study by Queck et al. (2008) and our research showed that Agr and RNAIII regulate some genes including $p s m \alpha 1-4$ and $p s m \beta 1-2$ in opposite ways, in both exponential phase and stationary phase, respectively. In addition, a recent study showed that $\delta$-toxin regulates colony spreading by inhibiting PSM binding to $S$. aureus surface (Kizaki et al., 2016). The role of RNAIII/ $\delta$-toxin in PSM regulated persister formation is worth further research.

Entry into stationary phase has been reported to promote expression of genes involved in sialic catabolism (Olson et al., 2013). Among the metabolism associated genes we studied by knockout and persister assay, only knockout of nanK, which was down-regulated by AgrCA and RNAIII (Figure 2), attenuated persister formation and L-form formation (Figure 5). It has been reported that ATP depletion is a key reason for persister increase in stationary phase (Conlon et al., 2016). However, no significant difference in ATP levels between $\Delta n a n K$ and its parent strain was found (Supplementary Figure S4), indicating the existence of other persister mechanisms independent of ATP depletion as being involved in Agr mediated persister formation in S. aureus. In addition, since sialic acid is more abundant in mucosa of hosts than in TSB (Mayer et al., 1964), the role of the sialic acid metabolism plays in Agr mediated persister formation might be more important in vivo and is worth further investigation in animal models.

L-form is an intriguing phenomenon and its mechanisms are not well unveiled in S. aureus (Owens and Nickerson, 1989; Michailova et al., 2007). Since L-form formation is closely related to cell wall integrity, a likely reason for NanK's role in L-form formation is that NanK deletion decreased the production of Fru-6-P, which is a substrate for synthesis of UDP-GlcNAc, a crucial molecule for cell wall building. Combined with our previous findings with GlpF (Han et al., 2014), our finding that NanK deletion attenuated both persister formation and L-form formation indicates the close relationship between formation of L-forms and persisters (Zhang, 2014).

In summary, by screening persister associated genes we showed that Agr system plays an important role in persister formation as seen by elevated persister levels in Agr mutants, in addition to its role in controlling virulence factors (Figure 6). The regulation of persister formation by Agr system is mainly carried out by PSMs. We also investigated the regulatory role of Agr system in sialic acid metabolism, which participates in persister formation and L-form formation. Our findings provide new insights into the biology of $S$. aureus persister formation and provides a possible explanation for the worsened bacteremia by Agr dysfunction in clinical treatments. 


\section{AUTHOR CONTRIBUTIONS}

$\mathrm{YZ}, \mathrm{W}-\mathrm{HZ}$, and TX designed the work and revised the manuscript. TX, X-YW, Y-MZ, and PC completed all the experiments. TX performed the statistically analysis, made the figures and wrote the manuscript.

\section{ACKNOWLEDGMENTS}

We thank Prof. Friedrich Götz, Tübingen University, Germany and Prof. Yunrong Chai, Northwestern University, United States for the help with $S$. aureus strains. This research was supported by the National Natural Science Foundation of China (81572046) and (81772231).

\section{REFERENCES}

Almagro-Moreno, S., and Boyd, E. F. (2009). Insights into the evolution of sialic acid catabolism among bacteria. BMC Evol. Biol. 9:118. doi: 10.1186/1471-21489- 118

Andrews, J. M. (2001). Determination of minimum inhibitory concentrations. J. Antimicrob. Chemother. 48(Suppl. 1), 5-16. doi: 10.1093/jac/48.suppl_1.5

Atshan, S. S., Shamsudin, M. N., Lung, L. T., Ling, K. H., Sekawi, Z., Pei, C. P., et al. (2012). Improved method for the isolation of RNA from bacteria refractory to disruption, including S. aureus producing biofilm. Gene 494, 219-224 doi: 10.1016/j.gene.2011.12.010

Baba, T., Bae, T., Schneewind, O., Takeuchi, F., and Hiramatsu, K. (2008) Genome sequence of Staphylococcus aureus strain Newman and comparative analysis of staphylococcal genomes: polymorphism and evolution of two major pathogenicity islands. J. Bacteriol. 190, 300-310. doi: 10.1128/JB.01000-07

Bae, T., and Schneewind, O. (2006). Allelic replacement in Staphylococcus aureus with inducible counter-selection. Plasmid 55, 58-63. doi: 10.1016/j.plasmid. 2005.05.005

Bigger, J. (1944). Treatment of staphylococcal infections with penicillin by intermittent sterilisation. Lancet 244, 497-500. doi: 10.1016/S0140-6736(00) 74210-3

Bruckner, R., Wagner, E., and Gotz, F. (1993). Characterization of a sucrase gene from Staphylococcus xylosus. J. Bacteriol. 175, 851-857. doi: 10.1128/jb.175.3. 851-857.1993

Bünter, J. P., Seth-Smith, H. M. B., Rüegg, S., Heikinheimo, A., Borel, N., and Johler, S. (2016). Wild type agr-negative livestock-associated MRSA exhibits high adhesive capacity to human and porcine cells. Res. Microbiol. 168, 130-138. doi: 10.1016/j.resmic.2016.09.006

Butterfield, J. M., Tsuji, B. T., Brown, J., Ashley, E. D., Hardy, D., Brown, K., et al. (2011). Predictors of agr dysfunction in methicillin-resistant Staphylococcus aureus (MRSA) isolates among patients with MRSA bloodstream infections. Antimicrob. Agents Chemother. 55, 5433-5437. doi: 10.1128/AAC.00407-11

Chatterjee, S. S., Joo, H. S., Duong, A. C., Dieringer, T. D., Tan, V. Y., Song, Y., et al. (2013). Essential Staphylococcus aureus toxin export system. Nat. Med. 19, 364-367. doi: 10.1038/nm.3047

Cheung, G. Y., Wang, R., Khan, B. A., Sturdevant, D. E., and Otto, M. (2011). Role of the accessory gene regulator agr in community-associated methicillinresistant Staphylococcus aureus pathogenesis. Infect. Immun. 79, 1927-1935. doi: 10.1128/IAI.00046-11

Cheverton, A. M., Gollan, B., Przydacz, M., Wong, C. T., Mylona, A., Hare, S. A., et al. (2016). A Salmonella toxin promotes persister formation through acetylation of tRNA. Mol. Cell. 63, 86-96. doi: 10.1016/j.molcel.2016. 05.002

Cohen, N. R., Lobritz, M. A., and Collins, J. J. (2013). Microbial persistence and the road to drug resistance. Cell Host Microbe 13, 632-642. doi: 10.1016/j.chom. 2013.05.009

\section{SUPPLEMENTARY MATERIAL}

The Supplementary Material for this article can be found online at: https://www.frontiersin.org/articles/10.3389/fmicb. 2017.02189/full\#supplementary-material

FIGURE S1 | (A-D) Exponential phase culture of USA500 and knockout mutants were treated with levofloxacin, oxacillin, gentamicin or vancomycin. (E) Persister levels of stationary phase cultures of USA500 and mutants. Results are representative of three independent experiments.

FIGURE S2 | Growth curve of USA500 and the two knockout mutants of psma 1-4 and psm $\beta 1-2$.

FIGURE S3 | Growth curve of USA500 and the its knockout mutants of nanK.

FIGURE S4 | Intracellular concentration of ATP in stationary phase USA500 and mutant strains. The values were adjusted according to the CFU count of each sample.

Conlon, B. P., Nakayasu, E. S., Fleck, L. E., Lafleur, M. D., Isabella, V. M., Coleman, K., et al. (2013). Activated ClpP kills persisters and eradicates a chronic biofilm infection. Nature 503, 365-370. doi: 10.1038/nature12790

Conlon, B. P., Rowe, S. E., Gandt, A. B., Nuxoll, A. S., Donegan, N. P., Zalis, E. A., et al. (2016). Persister formation in Staphylococcus aureus is associated with ATP depletion. Nat. Microbiol. 1:16051. doi: 10.1038/nmicrobiol. 2016.51

Conlon, B. P., Rowe, S. E., and Lewis, K. (2015). "Persister cells in biofilm associated infections," in Biofilm-Based Healthcare-Associated Infections, Vol. II, ed. G. Donelli (Cham: Springer International Publishing), 1-9.

Corrigan, R. M., Bellows, L. E., Wood, A., and Gründling, A. (2016). ppGpp negatively impacts ribosome assembly affecting growth and antimicrobial tolerance in Gram-positive bacteria. Proc. Natl. Acad. Sci. U.S.A. 113, E1710-E1719. doi: 10.1073/pnas.1522179113

Das, S., Lindemann, C., Young, B. C., Muller, J., Osterreich, B., Ternette, N., et al. (2016). Natural mutations in a Staphylococcus aureus virulence regulator attenuate cytotoxicity but permit bacteremia and abscess formation. Proc. Natl. Acad. Sci. U.S.A. 113, E3101-E3110. doi: 10.1073/pnas.15202 55113

Dhar, N., and McKinney, J. D. (2007). Microbial phenotypic heterogeneity and antibiotic tolerance. Curr. Opin. Microbiol. 10, 30-38. doi: 10.1016/j.mib.2006. 12.007

Diep, B. A., Carleton, H. A., Chang, R. F., Sensabaugh, G. F., and PerdreauRemington, F. (2006). Roles of 34 virulence genes in the evolution of hospitaland community-associated strains of methicillin-resistant Staphylococcus aureus. J. Infect. Dis. 193, 1495-1503. doi: 10.1086/503777

Dorr, T., Lewis, K., and Vulic, M. (2009). SOS response induces persistence to fluoroquinolones in Escherichia coli. PLOS Genet. 5:e1000760. doi: 10.1371/ journal.pgen.1000760

Dunman, P. M., Murphy, E., Haney, S., Palacios, D., Tucker-Kellogg, G., Wu, S., et al. (2001). Transcription profiling-based identification of Staphylococcus aureus genes regulated by the agr and/or sarA loci. J. Bacteriol. 183, 7341-7353. doi: 10.1128/JB.183.24.7341-7353.2001

Fauvart, M., De Groote, V. N., and Michiels, J. (2011). Role of persister cells in chronic infections: clinical relevance and perspectives on antipersister therapies. J. Med. Microbiol. 60(Pt 6), 699-709. doi: 10.1099/jmm.0.03 09320

Fowler, V. G., Sakoulas, G., McIntyre, L. M., Meka, V. G., Arbeit, R. D., Cabell, C. H., et al. (2004). Persistent bacteremia due to methicillin-resistant Staphylococcus aureus infection is associated with agr dysfunction and low-level in vitro resistance to thrombin-induced platelet microbicidal protein. J. Infect. Dis. 190, 1140-1149. doi: 10.1086/423145

Geiger, T., Goerke, C., Fritz, M., Schafer, T., Ohlsen, K., Liebeke, M., et al. (2010). Role of the (p)ppGpp synthase RSH, a RelA/SpoT homolog, in stringent response and virulence of Staphylococcus aureus. Infect. Immun. 78, 1873-1883. doi: 10.1128/iai.01439-09 
George, E. A., and Muir, T. W. (2007). Molecular mechanisms of agr quorum sensing in virulent staphylococci. Chembiochem $8,847-855$. doi: 10.1002/cbic. 200700023

Germain, E., Roghanian, M., Gerdes, K., and Maisonneuve, E. (2015). Stochastic induction of persister cells by HipA through (p)ppGpp-mediated activation of mRNA endonucleases. Proc. Natl. Acad. Sci. U.S.A. 112, 5171-5176. doi: $10.1073 /$ pnas. 1423536112

Gray, B., Hall, P., and Gresham, H. (2013). Targeting agr- and agr-Like quorum sensing systems for development of common therapeutics to treat multiple gram-positive bacterial infections. Sensors 13, 5130-5166. doi: 10. 3390/s130405130

Han, J., He, L., Shi, W., Xu, X., Wang, S., Zhang, S., et al. (2014). Glycerol uptake is important for L-form formation and persistence in Staphylococcus aureus. PLOS ONE 9:e108325. doi: 10.1371/journal.pone.0108325

Helle, L., Kull, M., Mayer, S., Marincola, G., Zelder, M. E., Goerke, C., et al. (2011). Vectors for improved Tet repressor-dependent gradual gene induction or silencing in Staphylococcus aureus. Microbiology 157(Pt 12), 3314-3323. doi: $10.1099 /$ mic. $0.052548-0$

Herbert, S., Ziebandt, A. K., Ohlsen, K., Schafer, T., Hecker, M., Albrecht, D., et al. (2010). Repair of global regulators in Staphylococcus aureus 8325 and comparative analysis with other clinical isolates. Infect. Immun. 78, 2877-2889. doi: 10.1128/IAI.00088-10

Hobby, G. L., Meyer, K., and Chaffee, E. (1942). Observations on the mechanism of action of penicillin. Exp. Biol. Med. 50, 281-285. doi: 10.3181/00379727-5013773

Ji, G., Beavis, R. C., and Novick, R. P. (1995). Cell density control of staphylococcal virulence mediated by an octapeptide pheromone. Proc. Natl. Acad. Sci. U.S.A. 92, 12055-12059. doi: 10.1073/pnas.92.26.12055

Joo, H.-S., Chatterjee, S. S., Villaruz, A. E., Dickey, S. W., Tan, V. Y., Chen, Y., et al. (2016). Mechanism of gene regulation by a Staphylococcus aureus toxin. mBio 7:e01579-16. doi: 10.1128/mBio.01579-16

Kang, C. K., Kim, Y. K., Jung, S. I., Park, W. B., Song, K. H., Park, K. H., et al. (2017). agr functionality affects clinical outcomes in patients with persistent methicillin-resistant Staphylococcus aureus bacteraemia. Eur. J. Clin. Microbiol. Infect. Dis. 36, 2187-2191. doi: 10.1007/s10096-0173044-2

Khan, B. A., Yeh, A. J., Cheung, G. Y. C., and Otto, M. (2015). Investigational therapies targeting quorum-sensing for the treatment of Staphylococcus aureus infections. Expert Opin. Investig. Drugs 24, 689-704. doi: 10.1517/13543784. 2015.1019062

Kim, Y., Wang, X., Ma, Q., Zhang, X. S., and Wood, T. K. (2009). Toxin-antitoxin systems in Escherichia coli influence biofilm formation through YjgK (TabA) and fimbriae. J. Bacteriol. 191, 1258-1267. doi: 10.1128/JB.01465-08

Kizaki, H., Omae, Y., Tabuchi, F., Saito, Y., Sekimizu, K., and Kaito, C. (2016). Cell-surface phenol soluble modulins regulate Staphylococcus aureus colony spreading. PLOS ONE 11:e0164523. doi: 10.1371/journal.pone.0164523

Korch, S. B., Henderson, T. A., and Hill, T. M. (2003). Characterization of the hipA7 allele of Escherichia coli and evidence that high persistence is governed by (p)ppGpp synthesis. Mol. Microbiol. 50, 1199-1213. doi: 10.1046/j.1365-2958. 2003.03779.x

Lechner, S., Lewis, K., and Bertram, R. (2012). Staphylococcus aureus persisters tolerant to bactericidal antibiotics. J. Mol. Microbiol. Biotechnol. 22, 235-244. doi: $10.1159 / 000342449$

Leung, V., and Lévesque, C. M. (2012). A stress-inducible quorum-sensing peptide mediates the formation of persister cells with noninherited multidrug tolerance. J. Bacteriol. 194, 2265-2274. doi: 10.1128/jb.06707-11

Lewis, K. (2007). Persister cells, dormancy and infectious disease. Nat. Rev. Microbiol. 5, 48-56. doi: 10.1038/nrmicro1557

Li, J., Ji, L., Shi, W., Xie, J., and Zhang, Y. (2013). Trans-translation mediates tolerance to multiple antibiotics and stresses in Escherichia coli. J. Antimicrob. Chemother. 68, 2477-2481. doi: 10.1093/jac/dkt231

Lina, G., Jarraud, S., Ji, G., Greenland, T., Pedraza, A., Etienne, J., et al. (1998). Transmembrane topology and histidine protein kinase activity of AgrC, the agr signal receptor in Staphylococcus aureus. Mol. Microbiol. 28, 655-662. doi: 10.1046/j.1365-2958.1998.00830.x

Livak, K. J., and Schmittgen, T. D. (2001). Analysis of relative gene expression data using real-time quantitative PCR and the $2^{-\Delta \Delta C_{t}}$ Method. Methods 25, 402-408. doi: 10.1006/meth.2001.1262
Ma, C., Sim, S., Shi, W., Du, L., Xing, D., and Zhang, Y. (2010). Energy production genes sucB and ubiF are involved in persister survival and tolerance to multiple antibiotics and stresses in Escherichia coli. FEMS Microbiol. Lett. 303, 33-40. doi: 10.1111/j.1574-6968.2009.01857.x

Maisonneuve, E., Castro-Camargo, M., and Gerdes, K. (2013). (p)ppGpp controls bacterial persistence by stochastic induction of toxin-antitoxin activity. Cell 154, 1140-1150. doi: 10.1016/j.cell.2013.07.048

Malachowa, N., Whitney, A. R., Kobayashi, S. D., Sturdevant, D. E., Kennedy, A. D., Braughton, K. R., et al. (2011). Global changes in Staphylococcus aureus gene expression in human blood. PLOS ONE 6:e18617. doi: 10.1371/journal.pone. 0018617

Mayer, F. C., Dam, R., and Pazur, J. H. (1964). Occurence of sialic acids in plant seeds. Arch. Biochem. Biophys. 108, 356-357. doi: 10.1016/0003-9861(64) 90398-4

Mechler, L., Herbig, A., Paprotka, K., Fraunholz, M., Nieselt, K., and Bertram, R. (2015). A novel point mutation promotes growth phase-dependent daptomycin tolerance in Staphylococcus aureus. Antimicrob. Agents Chemother. 59, 5366-5376. doi: 10.1128/AAC.00643-15

Michailova, L., Kussovsky, V., Radoucheva, T., Jordanova, M., and Markova, N. (2007). Persistence of Staphylococcus aureus L-form during experimental lung infection in rats. FEMS Microbiol. Lett. 268, 88-97. doi: 10.1111/j.1574-6968. 2006.00567.x

Mina, E. G., and Marques, C. N. (2016). Interaction of Staphylococcus aureus persister cells with the host when in a persister state and following awakening. Sci. Rep. 6:31342. doi: 10.1038/srep31342

Mitchell, A. M., Wang, W., and Silhavy, T. J. (2016). Novel RpoS-dependent mechanisms strengthen the envelope permeability barrier during stationary phase. J. Bacteriol. 199:e00708-16. doi: 10.1128/JB.00708-16

Moker, N., Dean, C. R., and Tao, J. (2010). Pseudomonas aeruginosa increases formation of multidrug-tolerant persister cells in response to quorum-sensing signaling molecules. J. Bacteriol. 192, 1946-1955. doi: 10.1128/jb.01231-09

Monk, I. R., Shah, I. M., Xu, M., Tan, M. W., and Foster, T. J. (2012). Transforming the untransformable: application of direct transformation to manipulate genetically Staphylococcus aureus and Staphylococcus epidermidis. mBio 3:e00277-11. doi: 10.1128/mBio.00277-11

Morfeldt, E., Taylor, D., von Gabain, A., and Arvidson, S. (1995). Activation of alpha-toxin translation in Staphylococcus aureus by the trans-encoded antisense RNA, RNAIII. EMBO J. 14, 4569-4577.

Mulcahy, L. R., Burns, J. L., Lory, S., and Lewis, K. (2010). Emergence of Pseudomonas aeruginosa strains producing high levels of persister cells in patients with cystic fibrosis. J. Bacteriol. 192, 6191-6199. doi: 10.1128/JB.01 651-09

Murray, E. J., Crowley, R. C., Truman, A., Clarke, S. R., Cottam, J. A., Jadhav, G. P., et al. (2014). Targeting Staphylococcus aureus quorum sensing with nonpeptidic small molecule inhibitors. J. Med. Chem. 57, 2813-2819. doi: 10. $1021 / \mathrm{jm} 500215 \mathrm{~s}$

Olson, M. E., King, J. M., Yahr, T. L., and Horswill, A. R. (2013). Sialic acid catabolism in Staphylococcus aureus. J. Bacteriol. 195, 1779-1788. doi: 10.1128/ jb.02294- 12

Otto, M. (2013). Staphylococcal infections: mechanisms of biofilm maturation and detachment as critical determinants of pathogenicity. Annu. Rev. Med. 64, 175-188. doi: 10.1146/annurev-med-042711-140023

Owens, W. E., and Nickerson, S. C. (1989). Morphologic study of Staphylococcus aureus L-form, reverting, and intermediate colonies in situ. J. Clin. Microbiol. $27,1382-1386$.

Painter, K. L., Krishna, A., Wigneshweraraj, S., and Edwards, A. M. (2014). What role does the quorum-sensing accessory gene regulator system play during Staphylococcus aureus bacteremia? Trends Microbiol. 22, 676-685. doi: 10.1016/ j.tim.2014.09.002

Park, S. Y., Chong, Y. P., Park, H. J., Park, K. H., Moon, S. M., Jeong, J. Y., et al. (2013). agr Dysfunction and persistent methicillin-resistant Staphylococcus aureus bacteremia in patients with removed eradicable foci. Infection 41, 111-119. doi: 10.1007/s15010-012-0348-0

Peschel, A., and Otto, M. (2013). Phenol-soluble modulins and staphylococcal infection. Nat. Rev. Microbiol. 11, 667-673. doi: 10.1038/nrmicro3110

Pu, Y., Zhao, Z., Li, Y., Zou, J., Ma, Q., Zhao, Y., et al. (2016). Enhanced efflux activity facilitates drug tolerance in dormant bacterial cells. Mol. Cell. 62, 284-294. doi: 10.1016/j.molcel.2016.03.035 
Queck, S. Y., Jameson-Lee, M., Villaruz, A. E., Bach, T. H., Khan, B. A., Sturdevant, D. E., et al. (2008). RNAIII-independent target gene control by the agr quorum-sensing system: insight into the evolution of virulence regulation in Staphylococcus aureus. Mol. Cell. 32, 150-158. doi: 10.1016/j.molcel.2008.08.005

Rose, W. E., Rybak, M. J., Tsuji, B. T., Kaatz, G. W., and Sakoulas, G. (2007). Correlation of vancomycin and daptomycin susceptibility in Staphylococcus aureus in reference to accessory gene regulator (agr) polymorphism and function. J. Antimicrob. Chemother. 59, 1190-1193. doi: 10.1093/jac/ dkm091

Schumacher, M. A., Balani, P., Min, J., Chinnam, N. B., Hansen, S., Vulic, M., et al. (2015). HipBA-promoter structures reveal the basis of heritable multidrug tolerance. Nature 524, 59-64. doi: 10.1038/nature14662

Schweizer, M. L., Furuno, J. P., Sakoulas, G., Johnson, J. K., Harris, A. D., Shardell, M. D., et al. (2011). Increased mortality with accessory gene regulator (agr) dysfunction in Staphylococcus aureus among bacteremic patients. Antimicrob. Agents Chemother. 55, 1082-1087. doi: 10.1128/aac.00918-10

Shan, Y., Brown Gandt, A., Rowe, S. E., Deisinger, J. P., Conlon, B. P., and Lewis, K. (2017). ATP-dependent persister formation in Escherichia coli. mBio 8:e02267-16. doi: 10.1128/mBio.02267-16

Shapiro, J. A., Nguyen, V. L., and Chamberlain, N. R. (2011). Evidence for persisters in Staphylococcus epidermidis RP62a planktonic cultures and biofilms. J. Med. Microbiol. 60(Pt 7), 950-960. doi: 10.1099/jmm.0.026013-0

Singh, R., Ray, P., Das, A., and Sharma, M. (2009). Role of persisters and smallcolony variants in antibiotic resistance of planktonic and biofilm-associated Staphylococcus aureus: an in vitro study. J. Med. Microbiol. 58(Pt 8), 1067-1073. doi: 10.1099/jmm.0.009720-0

Smyth, D. S., Kafer, J. M., Wasserman, G. A., Velickovic, L., Mathema, B., Holzman, R. S., et al. (2012). Nasal carriage as a source of agr-defective Staphylococcus aureus bacteremia. J. Infect. Dis. 206, 1168-1177. doi: 10.1093/infdis/ jis 483

Surewaard, B. G. J., de Haas, C. J. C., Vervoort, F., Rigby, K. M., DeLeo, F. R., Otto, M., et al. (2013). Staphylococcal alpha-phenol soluble modulins contribute to neutrophil lysis after phagocytosis. Cell Microbiol. 15, 1427-1437. doi: $10.1111 / \mathrm{cmi} .12130$

Tsuji, B. T., Harigaya, Y., Lesse, A. J., Sakoulas, G., and Mylotte, J. M. (2009). Loss of vancomycin bactericidal activity against accessory gene regulator (agr) dysfunctional Staphylococcus aureus under conditions of high bacterial density. Diagn. Microbiol. Infect. Dis. 64, 220-224. doi: 10.1016/j.diagmicrobio.2009. 01.028
Wang, R., Braughton, K. R., Kretschmer, D., Bach, T. H., Queck, S. Y., Li, M., et al. (2007). Identification of novel cytolytic peptides as key virulence determinants for community-associated MRSA. Nat. Med. 13, 1510-1514. doi: 10.1038/ $\mathrm{nm} 1656$

Wenjie, W., Jiazhen, C., Gang, C., Xin, D., Peng, C., Jing, W., et al. (2015). Transposon mutagenesis identifies novel genes associated with Staphylococcus aureus persister formation. Front. Microbiol. 6:1437. doi: 10.3389/fmicb.2015. 01437

World Health Organization (2017). Global Priority List of Antibiotic-Resistant Bacteria to Guide Research, Discovery, and Development of New Antibiotics. Available at: http://www.who.int/medicines/publications/global-priority-listantibiotic-resistant-bacteria/en/

Xu, T., Han, J., Zhang, J., Chen, J., Wu, N., Zhang, W., et al. (2016). Absence of protoheme IX Farnesyltransferase $\mathrm{CtaB}$ causes virulence attenuation but enhances pigment production and persister survival in MRSA. Front. Microbiol. 7:1625. doi: 10.3389/fmicb.2016.01625

Yee, R., Cui, P., Shi, W., Feng, J., and Zhang, Y. (2015). Genetic screen reveals the role of purine metabolism in Staphylococcus aureus persistence to Rifampicin. Antibiotics 4, 627-642. doi: 10.3390/antibiotics4040627

Zhang, Y. (2014). Persisters, persistent infections and the Yin-Yang model. Emerg. Microb. Infect. 3, e3. doi: 10.1038/emi.2014.3

Zhang, Y., Yew, W. W., and Barer, M. R. (2012). Targeting persisters for tuberculosis control. Antimicrob. Agents Chemother. 56, 2223-2230. doi: 10. 1128/aac.06288-11

Ziebandt, A. K., Becher, D., Ohlsen, K., Hacker, J., Hecker, M., and Engelmann, S. (2004). The influence of agr and sigmaB in growth phase dependent regulation of virulence factors in Staphylococcus aureus. Proteomics 4, 3034-3047. doi: 10.1002/pmic.200400937

Conflict of Interest Statement: The authors declare that the research was conducted in the absence of any commercial or financial relationships that could be construed as a potential conflict of interest.

Copyright (c) 2017 Xu, Wang, Cui, Zhang, Zhang and Zhang. This is an open-access article distributed under the terms of the Creative Commons Attribution License (CC BY). The use, distribution or reproduction in other forums is permitted, provided the original author(s) or licensor are credited and that the original publication in this journal is cited, in accordance with accepted academic practice. No use, distribution or reproduction is permitted which does not comply with these terms. 